\title{
Análise do desempenho de autocuidado em crianças com Síndrome de Down ${ }^{1,2}$
}

\author{
Viviane Ferreira da Silva ${ }^{a}$, Julie Souza Soares de Medeiros ${ }^{\mathrm{b}}$, Maria Natália Santos da Silva ${ }^{\mathrm{c}}$, \\ Leilane Silva de Oliveira ${ }^{\mathrm{d}}$, Renata de Magalhães Maurício Torres ${ }^{\mathrm{e}}$, \\ Maria Luiza Morais Regis Bezerra Ary ${ }^{\mathrm{f}}$
}

\author{
aTerapeuta ocupacional, Instituto Superior de Ciências da Saúde - INCISA, \\ Instituto Mineiro de Acupuntura e Massagem - IMAM, Belo Horizonte, MG, Brasil \\ ${ }^{b}$ Terapeuta ocupacional, Especialista em Terapia Ocupacional no Desenvolvimento Infantil, \\ Universidade Federal de Minas Gerais - UFMG, Belo Horizonte, MG, Brasil \\ 'Terapeuta ocupacional, Mestre em Psicologia Cognitiva, \\ Universidade Federal de Pernambuco - UFPE, Recife, PE, Brasil \\ ${ }^{\mathrm{d} A c a d e ̂ m i c a}$ do $5^{\circ}$ ano do curso de Terapia Ocupacional, Universidade Estadual de \\ Ciências da Saúde de Alagoas - UNCISAL, Maceió, AL, Brasil \\ 'Terapeuta ocupacional, Universidade Estadual de Ciências da Saúde \\ de Alagoas - UNCISAL, Maceió, AL, Brasil \\ ${ }^{\mathrm{f}}$ Terapeuta ocupacional, Professora assistente, Faculdade de Terapia Ocupacional, \\ Universidade Estadual de Ciências da Saúde de Alagoas - UNCISAL, Mestra em linguística, \\ Universidade Federal de Alagoas - UFAL e doutoranda em psicologia social, Maceió, AL, Brasil
}

\begin{abstract}
Resumo: A Síndrome de Down (SD), uma das mais frequentes anomalias dos cromossomos autossômicos e a mais antiga causa de retardo mental, é uma desordem genética diferenciada por apresentar uma série de características físicas e mentais específicas. Caracteriza-se por ser uma alteração na divisão cromossômica, resultando na triplicação do material genético referente ao cromossomo 21. O objetivo foi evidenciar o desempenho funcional na área de autocuidado de crianças com SD na faixa etária dos 3 aos 7 anos. Participaram da pesquisa 17 crianças com SD, assistidas na Associação de Pais e Amigos dos Excepcionais (APAE), utilizando-se o teste Inventário de Avaliação Pediátrica de Incapacidade (PEDI). Após a aplicação do teste observou-se que o desempenho funcional de crianças com SD é inferior ao de crianças sem a síndrome e que fatores externos como a inserção das crianças no processo escolar e o grau de escolaridade das cuidadoras interferem no desenvolvimento delas. O PEDI mostrou ser um instrumento importante para profissionais de saúde, em especial os terapeutas ocupacionais, visto que identifica a área específica em que a criança está em desvantagem, permitindo vislumbrar a possibilidade de intervir de forma estratégica nas dificuldades específicas de cada uma.
\end{abstract}

Palavras-chave: Autocuidado, Sindrome de Down, Terapia Ocupacional.

\section{Self-care functional development analysis of children with Down Syndrome}

\begin{abstract}
Down syndrome (DS) differs from other genetic disorders by presenting a specific group of physical and mental characteristics, representing one of the most usual abnormalities of autosomal chromosomes and being the oldest known cause of mental retardation. It is characterized by a change in chromosome division resulting in the tripling of genetic material on chromosome 21. Objective: Highlight the functional performance in the area of self-care with DS in children from three to seven years old. Methodology: Seventeen children with DS participated in the research, attended at the Association of Parents and Friends of the Mentally Disabled
\end{abstract}

Autor para correspondência: Viviane Ferreira da Silva, Unidade Maria Aparecida Cavalcanti Cerqueira, Associação Pestalozzi, Rua São Pedro, 20B, Village Campestre II, Cidade Universitária, CEP 57073-550, Maceió, AL, Brasil, e-mail: vivi_vfs@yahoo.com.br Recebido em 16/3/2011; $1^{\text {a }}$ Revisão em 8/8/2011; $2^{\text {a }}$ Revisão em 20/12/2011; Aceito em 3/3/2012. 
(APAE), using the Pediatric Evaluation Disability Inventory (PEDI). Result: After test application, it was possible to observe that the functional performance of children with DS is lower than that of children with no syndrome, and that external factors such as the inclusion of children in the school process and the educational level of caretakers interfere in the development of children. Conclusion: PEDI has proved to be an important tool for health professionals, mainly for occupational therapists, since it identifies the specific areas that children are disadvantaged, allowing the possibility to intervene strategically in the specific difficulties of each child.

Keywords: Self Care, Down Syndrome, Occupational Therapy.

\section{Introdução}

A Síndrome de Down é caracterizada como uma condição genética que leva seu portador a apresentar uma série de características físicas e mentais específicas (ANTUNES, 2004; PASTERNAK, 2007). Essa síndrome é considerada uma das mais frequentes anomalias dos cromossomos autossômicos e a mais antiga causa de retardo mental (ANTUNES, 2004; MANCINI et al., 2003), sendo os primeiros trabalhos científicos datados do século XIX (BUNDUKI et al., 1998; PESSOA, 2003).

Etiologicamente, caracteriza-se por ser uma alteração na divisão cromossômica usual, resultando na triplicação, ao invés da duplicação, do material genético referente ao cromossomo 21 (MOREIRA; EL-HANI; GUSMÃO, 2000). A causa dessa alteração ainda não é conhecida, mas sabe-se que ela pode ocorrer de três modos diferentes (ZELLWEGER, 1977 apud ANTUNES, 2004). Em 96\% dos casos, essa trissomia se apresenta por uma não disjunção cromossômica total: conforme o feto se desenvolve, todas as células acabam por assumir um cromossomo 21 extra (BISSOTO, 2005; BUNDUKI et al., 1998). Em cerca de $4 \%$ dos casos, entretanto, ou os portadores não têm todas as células afetadas pela trissomia, sendo denominados casos "mosaico" (entre 0,5\%-1,0\%), ou desenvolvem a Síndrome de Down por translocação gênica (entre 3,0\%-3,5\%), caso em que parte ou todo o cromossomo 21 extra se encontra ligado a outro cromossomo, geralmente o cromossomo 14 (BISSOTO, 2005; PASTERNAK, 2007).

A frequência da Síndrome de Down é de aproximadamente 1 para 800 nativivos, aumentando com a idade materna (PASTERNAK, 2007). Aos 40 anos, há uma chance de $1 \%$ de que um filho tenha um cromossomo extra e, com o avançar da idade, esse percentual pode aumentar (PASTERNAK, 2007; BARBOSA; CORRÊA, 1994). No Brasil, anualmente, nascem em torno de 8 mil portadores de Síndrome de Down (Mustacchi, 1990 apud ANTUNES, 2004; VOIVO, 2004). A expectativa de vida para os indivíduos com Síndrome de Down tem melhorado ao longo das últimas décadas e, nos dias atuais, os indivíduos com Síndrome de Down vivem até 40 anos ou mais (PASTERNAK, 2007; PESSOA, 2003).

A Síndrome de Down, em geral, pode ser diagnosticada durante a gestação, através do cariótipo, ao nascimento ou logo após, por suas características dismórficas, que variam entre os pacientes, mas sempre produzem um fenótipo característico (SCHWARTZMAN, 1999 apud SILVA; DESSEN, 2007). Existem cerca de 50 características físicas exibidas pela criança com Síndrome de Down logo após o nascimento (ANTUNES, 2004), entre elas estão: atraso no desenvolvimento mental e motor associada a sinais como hipotonia muscular (90,9\%) (SCHWARTZMAN, 1999 apud SILVA; DESSEN, 2007), prega palmar transversa única (59,0\%) (ANTUNES, 2004; BARBOSA; CORRÊA, 1994), prega única no quinto dedo $(18,1 \%)$, sulco entre o hálux e o segundo artelho (77,2\%), excesso de pele no pescoço (82\%) (SALVIO et al., 2007), fenda palpebral oblíqua (100\%), face achatada (86,3\%) (ANTUNES, 2004). Além do atraso no desenvolvimento, o portador da Síndrome de Down pode apresentar outros problemas de saúde, como: cardiopatia congênita (40\%) (BARBOSA; CORRÊA, 1994), problemas de audição (50\% a 70\%), de visão $(15 \%$ a $50 \%)$, alteraçôes na coluna cervical (1\% a 10\%), distúrbios da tireóide (15\%), problemas neurológicos (5\% a 10\%), obesidade e envelhecimento precoce (MANCINI, 2000).

No que se refere ao comportamento e padráo de desenvolvimento que a criança apresentará, é importante salientar que não há um padrão estereotipado e previsível em todas as crianças afetadas, uma vez que tanto o comportamento quanto os marcos motores e o desenvolvimento da inteligência não dependem exclusivamente da alteração cromossômica, mas também do potencial genético, bem como das influências derivadas do meio (ANTUNES, 2004; PAZIN; MARTINS, 2007). As crianças com Síndrome de Down seguem a mesma 
sequência de desenvolvimento das crianças normais, passando pelos mesmos marcos de desenvolvimento, entretanto pode haver diferenças quanto ao ritmo em que os marcos são alcançados, sendo ele mais lento (SOUZA, 2003). Assim, embora a Síndrome de Down seja classificada como uma deficiência mental, não se pode nunca predeterminar qual será o limite de desenvolvimento do indivíduo (PUESCHEL, 2003; ZELLWEGER, 1977 apud ANTUNES, 2004). Durante muito tempo, essas pessoas foram privadas de experiências fundamentais para o seu desenvolvimento porque não se acreditava que fossem capazes. Todavia, já é comprovado que crianças e jovens com Síndrome de Down podem alcançar estágios muito mais avançados de raciocínio e de desenvolvimento (PUESCHEL, 2003).

O desenvolvimento humano é um processo de evolução contínua, fruto de uma organização complexa que envolve desde os componentes biológicos até as relaçóes sociais e ambientais. Sendo assim, a aquisição de novas habilidades relaciona-se à faixa etária e às interaçôes vividas com os outros indivíduos de seu grupo social (AGUIAR et al., 2009). Alguns fatores podem impedir que este desenvolvimento ocorra normalmente e os fatores de risco materno são indubitavelmente citados em quase todas as pesquisas em que se abordam alteraçóes no desenvolvimento neuropsicomotor de criança, pela influência que exercem na vida do futuro adulto (CUNHA, 2008).

O desenvolvimento da funcionalidade na infância tem início com a aquisição de um amplo espectro de habilidades motoras que possibilitam à criança o domínio do seu corpo em diferentes posturas, sejam elas estáticas ou dinâmicas (HAUBENSTRICKER, 1986 apud FERREIRA et al., 2009). O conjunto dessas aquisições determina a função de mobilidade, elas apresentam íntima relaçáo com o desenvolvimento cognitivo. Tipicamente, os 3 primeiros anos de vida são marcados pelo amadurecimento neurosensorial representado pelas aquisiçóes motoras e aquisiçâo da linguagem. Dos 3 aos 7 anos, as alteraçôes motoras posturais tornam-se menos intensas, para dar lugar às expressóes cognitivas compreendendo argumentos lógicos, aspectos socioemocionais e comunicação gráfica (FERREIRA et al., 2009).

Algumas das características presentes na criança com Síndrome de Down impactam os sistemas ósteomúsculo-articular, levando à hipotonia, frouxidão ligamentar, diminuição da força muscular e controle motor, com consequente lentidão de movimentos, seleção de estratégias não usuais, atraso na aquisição e na combinação de padróes básicos de movimentos (FERREIRA et al., 2009). A associação de alteraçôes intelectuais e motoras acima citadas pode limitar em diferentes graus as habilidades de autocuidado e função social (VICARI, 2006).

É sabido que as aquisiçôes de autocuidado e função social estão relacionadas não só à capacidade de mobilidade para exploração do ambiente mas também à compreensão das habilidades percepto-motoras, de coordenação fina, comunicação e convivência social (HAUBENSTRICKER, 1986 apud FERREIRA et al., 2009). As alteraçóes anatômicas próprias da síndrome, como mãos pequenas com dedos curtos, a presença de uma prega palmar e ausência de alguns ossos do carpo dificultam a preensão e podem interferir diretamente na realização das tarefas de autocuidado (VICARI, 2006).

O objetivos desta pesquisa são investigar o desempenho de crianças portadoras de Síndrome de Down na faixa etária de 3 a 7 anos na área de autocuidado, por tratar-se de uma área bastante comprometida nessas crianças e que, por déficit de desenvolvimento, pode interferir nas relaçóes interpessoais; bem como identificar o perfil ocupacional e escolar de suas cuidadoras.

\section{Procedimentos metodológicos}

Trata-se de um estudo descritivo com corte transversal, realizado na Associação de Pais e Amigos dos Excepcionais (APAE), localizada na cidade de Maceió, Alagoas, no período de maio a setembro de 2009. A amostragem foi feita de forma intencional, não probabilística por conveniência, participando da pesquisa 17 crianças portadoras de Síndrome de Down na faixa etária de 3 a 7 anos, assistidas pela APAE, onde recebem atendimento de Terapia Ocupacional, e cujos responsáveis consentiram em participar da pesquisa, após serem informadas do objetivo, mediante a leitura e assinatura do termo de consentimento livre e esclarecido (TCLE). Foram determinados como critérios de exclusão crianças que apresentassem retardo mental grave e diagnóstico associado que comprometesse seu desempenho funcional.

A pesquisa foi desenvolvida em dois momentos. O primeiro foi de caráter observacional, no qual foi avaliado o desempenho das crianças participantes nos aspectos de autocuidado de acordo com a avaliação do PEDI. Posteriormente foram realizadas entrevistas com cada um dos cuidadores, com a finalidade de complementar os dados obtidos, visto que o local da pesquisa limitava a aplicação do teste em alguns itens (como o banho), e por alguns dados só poderem 
ser fornecidos pelos cuidadores, casos, por exemplo, do controle urinário e esfincteriano.

$\mathrm{O}$ instrumento utilizado no estudo foi o teste Pediatric Evaluation of Disability Inventory (PEDI), uma avaliação padronizada norte-americana que documenta de forma quantitativa a capacidade funcional da criança (habilidades) e a independência para realizar atividades de autocuidado, mobilidade e função social. Esse teste foi traduzido para o português e adaptado conforme as características socioculturais brasileiras, com autorização dos autores (MANCINI, 2000).

O PEDI consiste de um questionário estruturado que documenta o perfil funcional de crianças entre 6 meses e 7 anos e meio de idade. Esse perfil funcional informa sobre o desempenho de habilidades da criança (parte I), a respeito da independência ou quantidade de ajuda fornecida pelo cuidador (parte II) e sobre as modificaçôes do ambiente físico e doméstico utilizadas na rotina diária da criança (parte III) (MANCINI, 2000). Cada parte do teste disponibiliza informaçóes sobre três áreas de função: autocuidado, mobilidade e função social.

Neste estudo, foi utilizada a área de autocuidado das partes I, II e III correspondentes às habilidades funcionais, assistência do cuidador e modificação do ambiente. A primeira parte do teste PEDI contém 73 itens que englobam a avaliação funcional nos aspectos de textura dos alimentos, utilização de utensílios, utilização de recipientes de beber, higiene oral, cuidados com os cabelos, cuidados com o nariz, lavar as mãos, lavar o corpo e a face, vestimentas abertas na frente, fechos, calças, sapatos/meias, tarefas de toalete, controle urinário e controle intestinal. Os escores recebidos em cada item recebem pontuação de acordo com o desempenho, sendo zero por não conseguir desempenhar a função desejada e um por execução realizada, pontos posteriormente somados, produzindo escores totais de habilidades funcionais. Os escores produzidos de acordo com o PEDI sáo denominados como bruto, normativo e contínuo.

O escore bruto é a soma de todos os itens pontuados. $\mathrm{O}$ escore normativo refere-se ao desempenho esperado de crianças com desenvolvimento normal e da mesma faixa etária. É obtido por meio da transformação do escore total bruto em escores padronizados normativos através de tabelas específicas, com valores fixos. Um escore normativo de magnitude entre 30 e 70 é considerado dentro do intervalo de normalidade esperado para crianças brasileiras com desenvolvimento normal de mesma faixa etária (MANCINI et al., 2003). Escores normativos inferiores a 30 ilustram atraso ou desempenho significativamente inferior e escore normativo superior a 70 sugere uma criança com desempenho significativamente superior ao de crianças brasileiras com desenvolvimento normal e da mesma faixa etária (MANCINI, 2005). O escore contínuo fornece informação sobre o nível de capacidade da criança, não se levando em consideração a sua faixa etária (MANCINI, 2005).

A segunda parte do teste contém oito itens que contemplam alimentação, higiene pessoal, banho, vestir parte superior do corpo, vestir parte inferior do corpo, banheiro, controle urinário e controle intestinal. Nessa parte, cada item é avaliado numa escala ordinal de 0 a 5 , onde o escore zero informa que a criança é totalmente dependente do cuidador na realização da tarefa funcional e 5 indica que ela realiza a tarefa de forma independente. Escores intermediários informam sobre níveis diferenciados de ajuda fornecida pelo cuidador (máxima, moderada, mínima, supervisão) (MANCINI, 2000). Nessa parte, os escores recebidos em cada item são somados, resultando em escore total de independência funcional.

A terceira parte do teste refere-se às modificações necessárias para o desempenho das tarefas funcionais nos itens alimentação, higiene pessoal, banho, vestir parte superior do corpo, vestir parte inferior do corpo, banheiro, controle urinário e controle intestinal. Nesses componentes, as pontuaçôes são: $\mathrm{N}$ para nenhuma modificação; $\mathrm{C}$ para modificação centrada na criança (não especializada); R para equipamento de reabilitação; e E para modificaçôes extensivas. Essa parte foi cortada para que pudéssemos direcionar de forma mais objetiva nosso objeto de estudo.

Além desses componentes, também foram analisados outros fatores como: ocupaçáo e escolaridade das máes, bem como se as crianças estudam.

A entrevista foi do tipo semiestruturada, conduzida pelo próprio pesquisador.

\section{Resultados}

Das 17 crianças avaliadas pelo teste PEDI, 5,88\% estáo na faixa etária de 3 anos e 6 meses a 3 anos e 11 meses; $17,65 \%$ situam-se entre 4 anos e 4 anos e 5 meses; $17,65 \%$, entre 4 anos e 6 meses e 4 anos e 11 meses; $11,76 \%$, entre 5 anos e 5 anos e 5 meses; $5,88 \%$, entre 5 anos e 6 meses e 5 anos e 11 meses; $11,76 \%$, entre 6 anos e 6 anos e 5 meses; e 29,42\% entre 7 anos e 7 anos e 11 meses (Figura 1). Em relação à parte I do teste na área de autocuidado (Figura 2), o resultado alcançado pela criança 1 (C1), com idade entre 3 anos e 6 meses e 3 anos e 11 meses 
foi de 29 pontos no escore bruto, abaixo de 10 pontos no escore normativo e 48,58 no escore contínuo, com erro padrão de 2,14 pontos. Na faixa de idade entre 4 anos e 4 anos e 5 meses, foram obtidos pela criança 2 (C2): 20 pontos no escore bruto, abaixo de 10 pontos no escore normativo e 40,87 no escore contínuo, com erro padráo de 2,46 pontos. A criança 3 (C3) e a criança 4 (C4) obtiveram a mesma pontuação: 31 pontos no escore bruto, abaixo de 10 pontos no escore normativo e 50,07 no escore contínuo, com erro padrão de 2,11 pontos. Os seguintes resultados foram obtidos junto às crianças na faixa etária entre 4 anos e 6 meses e 4 anos e 11 meses: a criança 5 (C5) totalizou 51 pontos no escore bruto, 27,5 no escore normativo, com erro padrão de 3,0 pontos, e 64,68 no escore contínuo, com erro padrão de 2,22 pontos; a criança 6 (C6), 54 pontos no escore bruto, 31,1 no escore normativo, com erro padrão de 3,0 pontos, e 67,21 no escore contínuo, com erro padrão de 2,30 pontos; já a criança 7 (C7) alcançou 43 pontos no escore bruto, 16 no escore normativo com erro padrão de 3,9 pontos e 58,60 no escore contínuo com erro padrão de 2,09 pontos. Entre as crianças na faixa etária entre 5 anos e 5 anos e 5 meses, a criança 8 (C8) atingiu 33 pontos no escore bruto, abaixo de 10 pontos no escore normativo e 51,52 no escore contínuo, com erro padrão de 2,08 pontos; e a criança 9 (C9), 50 pontos no escore bruto, abaixo de 10 pontos no escore normativo e 66,88 no escore contínuo, com erro padrão de 2,20 pontos. A criança 10 (C10), cuja idade está entre 5 anos e 6 meses e 5 anos e 11 meses, obteve 52 pontos no escore bruto, abaixo de 10 pontos no escore normativo e 65,51 no escore contínuo, com erro padrão de 2,24 pontos. Em relação às crianças na faixa etária entre 6 anos e 6 anos e 5 meses, a criança 11 (C11) alcançou 61 pontos no escore bruto, 20,3 no escore normativo, com erro padrão de 4,0, e 74,23 no escore contínuo, com erro padráo de 2,69 pontos; e a criança 12 (C12), 53 pontos no escore bruto, abaixo de 10 pontos no escore normativo e 66,35 no escore contínuo, com erro padrão de 2,27 pontos.

Entre as crianças na faixa de idade de 6 anos e 6 meses a 6 anos e 11 meses não foi encontrada nenhuma que se enquadrasse no processo de inclusão da pesquisa e, finalizando o estudo, crianças com idade entre 7 anos e 7 anos e 11 meses atingiram os seguintes resultados: criança 13 (C13), 53 pontos no escore bruto, 23,1 no escore normativo, com erro padrão de 1,8 , e 66,35 no escore contínuo, com erro padrão de 2,27 pontos; criança 14 (C14), 35 pontos no escore bruto, abaixo de 10 pontos no escore normativo e 52,94 no escore contínuo, com erro padrão de 2,07 pontos; criança 15 (C15), 20 pontos no escore bruto, abaixo de 10 pontos no escore normativo e 40,87 no escore contínuo, com erro padrão de 2,46 pontos; criança 16 (C16), 49 pontos no escore bruto, 20,7 no escore normativo, com erro padrão de 1,8, e 63,09 no escore contínuo, com erro padrão de 2,18 pontos; e criança 17 (C17), 55 pontos no escore bruto, 24,4 no escore normativo com erro padrão de 1,9, e 68,10 no escore contínuo, com erro padrão de 2,34 pontos.

No que se refere à parte II (Figura 3) do teste, observou-se que a $\mathrm{C} 1$ obteve 11 pontos, tendo melhor desempenho nos aspectos alimentação, controles urinário e intestinal; a $\mathrm{C} 2$ alcançou 8 pontos, tendo igual pontuação em todos os itens; a C3 e a C4 também obtiveram a mesma pontuação nessa parte, conquistando 11 pontos cada, mas C3 destacou-se em alimentação, higiene pessoal e banho, e $\mathrm{C} 4 \mathrm{em}$ alimentação, higiene pessoal e vestir parte inferior do corpo. A C5 obteve 25 pontos, tendo destaque no item controle urinário. A C6 conquistou 30 pontos, com maior habilidade nos componentes alimentação, banho, controles urinário e intestinal. Já a C7 conquistou 21 pontos, com melhor desenvoltura em alimentaçáo, controles urinário e intestinal. A C8 alcançou 13 pontos, com maior habilidade em alimentaçáo. E a C9 atingiu 26 pontos, com maior desempenho na alimentação, controles urinário e intestinal.

A C10 obteve 26 pontos, com melhor desfecho nos aspectos de controles urinário e intestinal. Com 35 pontos, a C11 destaca-se por sua atuação em alimentação, controles urinário e intestinal. A C12 alcançou 31 pontos, com melhor desempenho em banho, controles urinário e intestinal. A C13 conquistou 30 pontos, mantendo melhor desempenho em controles urinário e intestinal. A C14, com 16 pontos, obteve desempenho igual em todos os itens. A C15 obteve 3 pontos, o pior desempenho entre os participantes, conseguindo pontuar apenas nos itens alimentação, controles urinário e intestinal. A C16, com 26 pontos, teve destaque nos controles urinário e intestinal. E a $\mathrm{C} 17$ com 31 pontos, destacou-se no banho.

$\mathrm{Na}$ segunda parte da pesquisa observou-se que, em relação à escolaridade das crianças, 52,95\% estudavam em escola regular e $47,05 \%$ não estudavam, sendo a queixa principal das crianças não estarem frequentando a escola, o fato de não acompanharem a turma ou atrapalharem o andamento da classe.

No que diz respeito às atividades profissionais, $17,65 \%$ das mães trabalhavam fora de casa e $82,35 \%$, em casa, muitas relataram ter abandonado a profissão para dar maior assistência aos filhos. A respeito da 
escolaridade média das cuidadoras das crianças com Síndrome de Down, evidenciou-se que das 17 mães, $11,76 \%$ eram analfabetas, $35,30 \%$ tinham o ensino fundamental incompleto, $23,53 \%$, o ensino médio incompleto, $17,65 \%$ tinham o ensino médio completo, $5,88 \%$ tinham ensino superior incompleto e 5,88\% tinham ensino superior completo (Figura 4). Esses dados exploratórios traçam questóes acerca do grau de instrução das cuidadoras e sobre como eles podem influenciar no suporte social, familiar, na autonomia e no desempenho funcional das crianças. Estudos recentes apontam a baixa escolaridade materna como um dos fatores que interferem no desenvolvimento neuropsicomotor infantil (LAMY FILHO et al., 2008, 2008; CUNHA, 2008; AGUIAR et al., 2009). Cunha (2008) lembra que a escolaridade possibilita à mãe compreender a importância das primeiras relaçóes da díade mãe-filho, induzindo à ampla estimulação sensorial e intelectual, a maior tempo de alimentação natural, sono tranquilo, aquisição rápida de linguagem, socialização e a experiências perceptivamente positivas, contribuindo positivamente para o desenvolvimento da criança.

Durante as entrevistas com as cuidadoras, as que possuíam grau de escolaridade menor relataram espontaneamente que limitavam a participação das crianças em funçôes como, vestir roupas, amarrar sapatos e banho devido à falta de tempo e ao fato de as crianças executarem essas tarefas de forma mais lenta. Uma vez que a incorporação de uma tarefa no comportamento determina a habilidade, a realização e repetição da tarefa, mesmo de forma lenta e ineficaz, são necessárias para a organização e o aprendizado adequados (FERREIRA et al., 2009).

\section{Discussão}

Levando-se em conta que a criança tem características próprias, necessidades e possibilidades ilimitadas para se desenvolver (NICOLAU, 1997; SALVIO et al., 2007), cada momento constitui-se em possibilidade de vivências, buscas, experimentaçáo, descobertas.

Em cada idade, o movimento toma características significativas e a aquisição ou aparição de determinados comportamentos motores tem repercussôes importantes no desenvolvimento da criança (NICOLAU, 1997). Abrange modificações no plano físico ou motor (capacidade para realizar movimentos), no plano intelectual (capacidade para pensar e raciocinar), no plano emocional (capacidade para sentir) e no plano social (capacidade para relacionar-se com os outros), sendo regido e influenciado por fatores genéticos e ambientais (ANDRADE; LUFT; ROLIM, 2004). De modo geral, considera-se que existe atraso no desenvolvimento quando uma criança não atinge os marcos na idade prevista (ANDRADE; LUFT; ROLIM, 2004).

Diante dessa afirmativa, observaram-se os seguintes resultados em relação à parte I do teste: $94,12 \%$ das crianças apresentaram atraso no desempenho - 58,82\% obtiveram pontuação abaixo de $10 ; 35,30 \%$ atingiram desempenho fora da média (inferior a 30 pontos); e apenas $5,88 \%$ alcançaram bom desempenho (31 pontos), média prevista para uma criança que náo apresenta nenhum comprometimento motor $\mathrm{e}$ cognitivo, segundo o escore normativo de Mancini (2005) (Figura 5). Esses achados confirmam evidências existentes na literatura, no que se refere ao atraso no desenvolvimento de crianças com Síndrome de Down (CONNOLLY; MORGAN; RUSSEL, 1984; GARCIAS et al., 1995; SALVIO et al., 2007).

Durante a aplicaçáo do teste, os itens com maior grau de dificuldade foram o de fechos e vestimentas, devido à necessidade de maior habilidade para sua execução. No que concerne aos fechos, apenas $11,76 \%$ das crianças obtiveram a pontuaçáo 2 nesse item; $52,94 \%$ conseguiram a pontuação 1; e 35,30\% obtiveram pontuação 0 . Porém, deve-se levar em consideração que a idade média para a aquisiçáo dessa habilidade é de 4 a 5 anos (PESSOA, 2003). Em relaçáo às vestimentas, 58,83\% obtiveram pontuação abaixo de 3 e $41,17 \%$ atingiram 3 pontos ou mais, porém nenhuma criança obteve a pontuaçáo máxima. Segundo Pessoa (2003), a criança com desenvolvimento normal veste-se sem nenhuma ajuda ou supervisão a partir dos 4-6 anos de idade.

Nos componentes de toalete, apenas $29,41 \%$ das crianças conseguiram atingir pontuação a partir de 3 pontos e $70,59 \%$ perfizeram menos de 3 pontos neste item.

No aspecto de lavar e secar as mãos, apesar de ser uma tarefa básica, adquirida aos 2-3 anos de idade (RAMALHO; PEDREMÔNICO; PERISSINOTO, 2000), apenas $52,95 \%$ conseguiram 4 pontos ou mais e $47,05 \%$ atingiram pontuação inferior.

No que diz respeito à parte II do teste, os resultados obtidos no desempenho funcional das crianças avaliadas foram abaixo do esperado, tendo melhor resultado as crianças compreendidas na faixa etária entre 6 anos e 6 anos e 5 meses. E o pior desempenho foi o das crianças entre 4 anos e 4 anos e 5 meses (Figura 3).

Diante do exposto, $60 \%$ daqueles cujas mães possuíam maior grau de escolaridade (a partir do ensino médio completo) obtiveram melhor 
desempenho funcional em relação às demais crianças avaliadas, corroborando a afirmativa de Antunes (2004), o qual menciona que o desenvolvimento da criança depende muito do envolvimento e participação dos pais no estímulo à criança em casa, por meio de um ambiente familiar facilitador e de proteção. Outro fator relevante encontrado na pesquisa foi que, das crianças que frequentam a escola, 66,66\% alcançaram melhor desempenho funcional comparadas às demais crianças avaliadas, de acordo com a idade, visto que a inserçáo da criança no processo escolar favorece o desenvolvimento nas áreas cognitiva, social e motora (GALVÃO; CAVALCANTI, 2007; SOUZA, 2003).

A família e a escola são duas instituiçôes que exercem um papel de grande importância no desenvolvimento dos indivíduos (SILVA; DESSEN, 2007). A família pode orientar, incentivar e fornecer oportunidades de experiência à criança, como o cuidado e higiene pessoal, durante as atividades de vestuário, banho e alimentação, fornecendo tempo adequado para a criança praticá-las no seu cotidiano (GALVÃO; CAVALCANTI, 2007). E a escola inclui não só a socialização e participação nas atividades acadêmicas como também a participação ativa em atividades funcionais que dáo suporte para as competências de maior incorporação de regras sociais e diminuição de comportamentos agressivos (GALVÃO; CAVALCANTI, 2007; VOIVO, 2004).

Desse modo, a partir dos resultados obtidos através do PEDI é possível direcionar um plano de tratamento específico, processo onde a atuação do terapeuta ocupacional junto à equipe profissional é de fundamental relevância, por meio de uma intervenção precoce na promoção de aquisiçấo das habilidades, proporcionando maior independência e menor impacto de problemas na vida futura da criança.

O terapeuta ocupacional pode auxiliar no desenvolvimento de crianças com Síndrome de Down através de sua atuação, dando enfoque ao desempenho ocupacional, no qual deve visar não só o aumento da capacidade funcional, mas também que a criança tenha maior habilidade para interagir com o ambiente físico e social, de forma a se engajar em atividades de seu interesse, conseguindo participar ou mesmo organizar rotinas diárias satisfatórias, que incluam as tarefas de autocuidado.

\section{Conclusão}

As atividades de autocuidado são tarefas ocupacionais importantes no desenvolvimento neuropsicomotor da criança, sendo fundamentais para a aquisição de marcos motores, independência funcional, autonomia e para a construçáo da autoestima e autoconfiança da criança. As manifestações apresentadas por crianças com a Síndrome de Down podem ser expressas funcionalmente, interferindo no desempenho de forma independente em diversas atividades e tarefas da rotina diária dessas crianças.

O presente estudo apresenta evidências de que o desempenho funcional nas atividades de autocuidado de crianças com Síndrome de Down é inferior ao de crianças sem a síndrome, e que fatores externos, como a inserção das crianças no processo escolar e maior grau de escolaridade das cuidadoras interferem no desenvolvimento delas, que apresentam melhor desempenho no teste.

O PEDI mostrou ser um instrumento importante para os profissionais de saúde, em especial os terapeutas ocupacionais, visto que identifica a área específica em que a criança está em desvantagem, permitindo vislumbrar a possibilidade de intervir de forma estratégica nas dificuldades especificas de cada criança, através de um olhar personalizado em relação às suas necessidades, traçando táticas viáveis para $\mathrm{o}$ plano de tratamento, de maneira a favorecer a melhor aquisição de suas habilidades, proporcionando-lhe maior independência no seu dia a dia.

\section{Referências}

AGUIAR, L. C. V. et al. Prevalência de atrasos no desenvolvimento neuropsicomotor em crianças de 06 a 24 meses. In: ENCONTRO LATINO AMERICANO DE INICIAÇÃO CIENTÍFICA, 11.; ENCONTRO LATINO AMERICANO DE PÓS-GRADUAÇÃO, 7., 2009, São José dos Campos. Anais... São José dos Campos: Universidade do Vale do Paraíba, 2009. p. 1588-1591.

ANDRADE, A.; LUFT, C. B.; ROLIM, M. K. S. B. O desenvolvimento motor, a maturaçáo das áreas corticais e a atenção na aprendizagem motora. Revista Digital, Buenos Aires, v. 10, n. 78, p. 3-4, nov. 2004.

ANTUNES, G. A. A. O enfrentamento da Sindrome de Down: Uma abordagem do comportamento materno e do tratamento fisioterapêutico. 2004. 27 f. Monografia (Graduação em Fisioterapia)-Universidade Federal de Goiás, Goiânia, 2004. Disponível em: <http://www.ucg. br/ucg/institutos/nepss/monografia/monografia_15.pdf $>$. Acesso em: 15 mar. 2009.

BARBOSA, A. C. A.; CORRÊA, C. A. I. C. Programa de orientação domiciliar de famílias com crianças com Síndrome de Down. Cadernos de Terapia Ocupacional da UFSCar, São Carlos, v. 4, n. 1-2, p. 83-85, 1994.

BISSOTO, M. L. O desenvolvimento cognitivo e o processo de aprendizagem do portador de Síndrome de Down: Revendo concepçōes e perspectivas educacionais. Ciências \& Cognição, Rio de Janeiro, v. 4, p. 85-6, 2005.

BUNDUKI, V. et al. Rastreamento da síndrome de Down com uso de escore de múltiplos parâmetros ultrasonográficos. Revista Brasileira de Ginecologia e Obstetrícia, 
Rio de Janeiro, v. 20, n. 9, p. 525-531, out. 1998. http:// dx.doi.org/10.1590/S0100-72031998000900006

CONNOLLY, B. H.; MORGAN, S.; RUSSEL, F. F. Evaluation of children with Down syndrome who participated in an early intervention program. Physical Therapy, Alexandria, v. 64, n. 10, p. 1515-1519, Oct 1984.

CUNHA, H. L. Avaliação do desenvolvimento neuropsicomotor em crianças na rede básica de saúde utilizando o teste de Denver II: Identificação de fatores de risco materno. 2008. 87 f. Tese (Doutorado em Ciências da Saúde)-Universidade Federal do Rio Grande do Norte, Natal, 2008.

FERREIRA, D. M. et al. Funcionalidade de crianças com e sem Síndrome de Down. Revista Neurociências, São Paulo, v. 17, n. 3, p. 231-8, 2009.

GALVÃO, C. R. C.; CAVALCANTI, A. A. S. Terapia ocupacional: Fundamentação e prática. 1. ed. Rio de Janeiro: Guanabara Koogan, 2007.

GARCIAS, G. L. et al. Aspectos do desenvolvimento neuropsicomotor na Síndrome de Down. Revista Brasileira de Neurologia, Rio de Janeiro, v. 31, n. 6, p. 245-248, nov./dez. 1995.

LAMY FILHO, F. et al. Ambiente domiciliar e alteraçóes do desenvolvimento em crianças de comunidade da periferia de São Luís - MA. Ciência e Saúde Coletiva, Rio de Janeiro, v. 16, n. 10, p. 4181-4187, out. 2011. http://dx.doi.org/10.1590/S1413-81232011001100023

MANCINI, M. C. Inventário de avaliação pediátrica de incapacidade (PEDI): Manual da versão brasileira adaptada. 1. ed. Belo Horizonte: UFMG, 2005.

MANCINI, M. C. Pediatric Evaluation of Disability inventory $(P E D I)$. Belo Horizonte: Laboratórios de Atividade e Desenvolvimento Infantil (UFMG), 2000. Disponível em: <http://www.ufmg.br/proex/arquivos/ co_coordcomext_semananais.pdf $>$. Acesso em: 22 jun. 2009.

MANCINI, M. C. et al. Comparação do desempenho funcional de crianças portadoras de Síndrome de Down e crianças com desenvolvimento normal aos 2 e 5 anos de idade. Arquivos de Neuro-Psiquiatria, São Paulo, v. 61, n. 2-B, p. 2-3, jun. 2003. http://dx.doi.org/10.1590/ S0004-282X2003000300016
MOREIRA, L. M. A.; EL-HANI, C. N.; GUSMÃO, F. A. F. Down syndrome and its pathogenesis: considerations about genetic determinism. Revista Brasileira de Psiquiatria, São Paulo, v. 22, n. 2, p. 96-99, jun. 2000. http://dx.doi. org/10.1590/S1516-44462000000200011

NICOLAU, M. L. M. Educação pré-escolar: fundamentos e didática. 5. ed. São Paulo: Ática, 1997.

PASTERNAK, J. J. Uma introdução à genética molecular humana: mecanismos das doenças hereditárias. 2. ed. Rio de Janeiro: Guanabara, 2007.

PAZIN, A. C.; MARTINS, M. R. I. Desempenho funcional de crianças com Síndrome de Down e a qualidade de vida de seus cuidadores. Revista Neurociência, São Paulo, v. 15, n. 4, p. 297-303, 2007.

PESSOA, J. H. L. Desenvolvimento da criança, uma visão pediátrica. Revista Brasileira de Medicina, Rio de Janeiro, v. 9, n. 3, p. 15-6, 2003.

PUESCHEL, S. (Org.). Sindrome de Down: guia para pais e educadores. Tradução de L. H. Reily. Campinas: Papitus, 2003.

RAMALHO, C. M. J.; PEDREMÔNICO, M. R.; PERISSINOTO, J. Síndrome de Down: avaliação do desempenho motor, coordenação e linguagem (entre dois e cinco anos). Temas Sobre Desenvolvimento, São Paulo, v. 9, n. 52, p. 11-14, 2000.

SALVIO, C. C. et al. Congenital epiphora in patients with Down syndrome. Arquivos Brasileiros de Oftalmologia, São Paulo, v. 70, n. 3, p. 423-427, maio/jun. 2007. http:// dx.doi.org/10.1590/S0004-27492007000300007

SILVA, N. L. P.; DESSEN, M. A. Crianças com e sem Síndrome de Down: valores e crenças de pais e professores. Revista Brasileira de Educação Especial, Marília, v. 13, n. 3, p. 429-446, 2007. http://dx.doi.org/10.1590/ S1413-65382007000300009

SOUZA, A. M. C. A criança especial: Temas médicos, educativos e sociais. 1. ed. São Paulo: Roca, 2003.

VOIVO, M. A. Inclusão escolar de crianças com Sindrome de Down. 2. ed. Rio de Janeiro: Vozes, 2004.

VICARI, S. Motor Development and Neuropsychological Patterns in Persons with Down Syndrome. Behavior Genetics, New York, v. 36, n. 3, p. 355-64, May 2006. http://dx.doi.org/10.1007/s10519-006-9057-8

\section{Contribuição dos Autores}

Viviane Ferreira da Silva foi a principal colaboradora; Maria Luiza Morais Regis Bezerra Ary foi a orientadora; e as demais autores foram auxiliares em todo o processo.

\section{Notas}

${ }^{1}$ Estudo descritivo desenvolvido após aprovação pelo Comitê de Ética em Pesquisa em Seres Humanos da Uncisal e da Associação de Pais e Amigos dos Excepcionais de Maceió (APAE) e mediante assinatura da responsável através do Termo de Consentimento Livre e Esclarecido (TCLE).

${ }^{2}$ Estudo apresentado parcialmente sob forma oral no VIII Congresso Norte-Nordeste de Terapia Ocupacional em 2010, em Recife, Pernambuco, Brasil. 